\title{
Literatura e religião: domínios e(m) relações dialógicas
}

Éderson Luís Silveira ${ }^{1}$

http://orcid.org/0000-0002-8483-4656 http://lattes.cnpq.br/9636609353277293

Wilder Kleber Fernandes de Santana ${ }^{2}$

http://lattes.cnpq.br/4768062692409818

Enviado em: 18/09/2018

Aceito em: 18/11/2018

RESUMO: A literatura e a religião podem ser percebidas como objetos de saber inter-relacionados. A partir do prisma dialógico, tais relações podem ser explicitadas sem esgotamento considerando-se que os discursos produzidos são atravessados por enunciados de outrem. Assim, o pesquisador, mais do que reconhecer a necessidade de escapar de esquemas interpretativos estabelecidos a priori, reconhece que a pesquisa se realiza na presença do discurso do outro que o constitui. Nessa linhagem de discussões teórico-analíticas, esse artigo delimita duas propostas de desenvolvimento: a) Discursivizar a importância das Relações dialógicas para a interpretação dos saberes religiosos e literários e b) Analisar, dialogicamente, o poema "A falta que ama", de Adélia Prado, em seu livro $O$ coração disparado. Conclui-se que tanto poema quanto religiosidade remetem a uma linguagem metapoética que está relacionada a uma falta constitutiva do escrever e que diz respeito aos modos de (in)definição de experiência com o sagrado.

Palavras-chave: Religiosidade; Dialogismo; Bakhtin.

ABSTRACT: Literature and religion may be perceived as objects of wonder inter-related. From the Prism Dialogic such relationships can be explained without exhaustion since the discourse produced through statements of others. Thus, the researcher, more than recognize the need to escape from the interpretative schemes established a priori, acknowledges that the research takes place in the presence of another that is. In this line of theoretical and analytical discussions this article delimits two development proposals: a) Discursivizar the importance of the dialogical Relationships for the interpretation of religious and literary knowledge and b) Analyze, based on Bakhtin, the poem "A falta que ama ", of Adelia Prado, in your book the heart racing. It is concluded that both poem as religiosity refer to an implicit poetic language that is related to a lack of writing and respect to (UN) definition of experience with the sacred.

Keywords: Religiosity; Dialogic; Bakhtin.

\section{Discussões em torno da Religião e da Literatura}

A relação entre literatura e religião tem tomado espaços múltiplos e(m) expressões de produtividade acadêmica cujos pressupostos filosófico-ideológicos nos fazem pensar estas

\footnotetext{
${ }^{1}$ Doutorando e Mestre em Linguística pela Universidade Federal de Santa Catarina - UFSC; Membro do Grupo de Pesquisa em Territorialidades e Infância e Formação Docente (GESTAR/CNPq), do grupo Formação de Porfessores de Língua e Literaturas (FORPROLL/CNPq) e da Associaçao de Linguística Aplicada do Brasil - ALAB

2 Doutorando em Linguística (Proling - UFPB, 2018); Mestre em Linguística (Proling - UFPB, 2016); Mestre em Teologia (Faculdade Teológica Nacional, 2016); Mestrando em Arqueologia Bíblica (Faculdade Teológica Nacional, 2017); Especialista em Gestão da Educação Municipal (UFPB, 2017); Poeta e Escritor Paraibano.
} 
duas grandes esferas como interdiscursivas, uma vez que ambas se constituem, dialogicamente, nas lentes da história ${ }^{3}$. Vattimo (2004), por exemplo, assevera que a relação entre literatura e religião é constitutiva da cultura moderna, o qual traz enfoque às implicações da herança judaico-cristã, enquanto "religião do livro". Nesse percurso interpretativo, alguns dos saberes construídos e desenvolvidos são o antropológico e o soteriológico ${ }^{4}$, enquanto instâncias simbólicas intrínsecas.

Em termos dialógicos (2006 [1979]) a história, enquanto um horizonte cronotópico ${ }^{5}$ de acontecimentos discursivos, convoca centros de saber em que tanto o todo quanto as margens de cada fato são elencados para a interpretação (hermenêutica). Desse modo, são analisadas também as consequências para a consciência ${ }^{6}$ histórico-cultural dos seres humanos, mormente no Ocidente, tal como examinado por Gianni Vattimo (2004). Em relação ao conceito bakhtiniano de cronotopo vale acentuar, antes de prosseguirmos, que ele nos serve de referência para localizar discursos no tempo e no espaço extrapolando o contexto de enunciação:

O que dissermos aqui, ou em outro lugar, será sempre um ponto de vista posicionado num espaço de relações que extrapolam o ambiente vivencial de quem percebe o mundo daquele lugar, deixando à mostra os excedentes de visão que interagem neste mesmo espaço (MACHADO, 2010, p. 206)

O cronotopo foi concebido como uma forma arquitetônica da narrativa que configura modos de vida em contextos particulares de temporalidades. O tempo, para Bakhtin, torna-se pluralidade de visões de mundo: tanto na experiência como na criação, manifesta-se como um conjunto de simultaneidades que não são instantes, mas acontecimentos no complexo de seus desdobramentos. A pluralidade de que fala Bakhtin só pode ser apreendida no grande tempo das culturas e civilizações, quer dizer, no espaço. (MACHADO, 2010, p. 215)

Partimos do pressuposto de que há ausência de trabalhos empenhados na área, corroborando com algumas reflexões feitas por Magalhães (2009), o qual confronta a importância desse tema com seu apagamento na agenda de reflexões na atualidade. O pesquisador reitera que, embora haja tentativas particularizadas de um esboço desses estudos, não existe, ainda, "um projeto que aponte para um diálogo permanente" (MAGALHÃES, 2009, p. 23).

Nessa linhagem de discussões teórico-analíticas, esse artigo delimita duas propostas de desenvolvimento: a) Discursivizar a importância das Relações dialógicas para a interpretação dos saberes religiosos e literários e b) Analisar, dialogicamente, o poema "A falta que

\footnotetext{
${ }^{3}$ Não estamos tratando, aqui, de história enquanto disciplina escolar, nem enquanto curso universitário. Antes, nosso olhar concebe a história enquanto cronotopo, categoria bakhtiniana a qual unifica tempo e espaço como condicionantes para os acontecimentos literários e humanos, na agenda de narrativas que perpassam os sujeitos em níveis ético, estético e cognitivo.

${ }^{4} \mathrm{O}$ saber soteriológico, mobilizado pela Teologia, consiste no princípio de atributos ligados à salvação da humanidade. Tal termo, provindo do grego $\sigma \omega \tau \dot{\eta} \varrho ı$ [Soterios - Salvação], e $\lambda$ ójos [logos - palavra], sublima a religião como re-ligare, no constante religar ao divino. Ao colocarem seus anseios diante de Deus, os sujeitos por meio da fé na divindade, adquirem determinadas práticas em consonância com a vontade do divino acreditando que, dessa forma, ascenderão a uma dimensão de paz, satisfação, alegria. Essa, na medida em que recebe nomes como céu, paraíso, casa celeste, são o indicativo de sua salvação.

5 Oriundo das expressões cronos: tempo e topo: lugar diz respeito às relações espaço-tempo.

${ }^{6}$ Vale acentuar que em Bakhtin o termo consciência está amalgamado de um contexto teórico particular:
}

Na percepção de Bakhtin, falar sobre consciência é falar sobre linguagem, pois a consciência só pode surgir e se afirmar como realidade por meio da encarnação material em signos. Portanto, a consciência só se torna consciência quando se impregna de conteúdo ideológico e somente no processo de interação social, na assimilação de discursos alheios. Para Bakhtin, a consciência é um fato socioideológico, e sua lógica é a da comunicação ideológica, da interação semiótica de um grupo social. (CÔRREA; RIBEIRO, 2012, p. 333) 
ama” (p. 60), de Adélia Prado, em seu livro O coração disparado (2012).

Alguns dos autores que subsidiaram nossos dizeres, tanto em perspectiva da linguagem quanto em vieses literário e religioso, são Bakhtin (2006 [1979]); 2010 [1965], Medviédev (2016 [1928]), Todorov (2011), Magalhães (2009), Santana e Francelino (2018). Para realização de nosso ato analítico, trabalhamos com as categorias autor-criador, heterogeneidade, eu-para-mim e eu-para-outro, consciência, folclore e religião.

Tais reflexões, na produtividade da interpretação sobre o profano e o sagrado, potencializam a noção de linguagem e discurso, por causa da produção discursiva de teor ontológico, literário e filosófico que as atravessa enquanto saberes constituídos na modernidade. Para Eliade (1992) a visão do ser humano como participante de algo maior - perspectiva não partilhada na Modernidade ou frequentemente rechaçada - fez com que a relação com entre os seres humanos e a natureza ou a relação com as divindades permitisse ampliar o escopo de conhecimento acerca da complexidade humana visando trazer explicações sobre o mundo, a vida e formas de se posicionar e ler o universo à nossa volta. Isso porque, para o autor, a dessacralização do mundo, ainda que mais extrema, não abole completamente a existência do sagrado. Desse modo, a sacralização do tempo resulta num regresso simbólico ao tempo dos deuses e dos atos de criação que faz com que haja reiteração de rituais, repetições e formas de agir, o que atribui ao divino uma participação na vida em comunidade (o que não quer dizer que não haja formas profanas ${ }^{7}$ de existência onde se concebe o tempo como puramente humano onde não cabe aos deuses a possibilidade de participação, como na Modernidade).

Dessa forma, a importância de analisar a participação da religião e da religiosidade na vida dos seres humanos se dá porque há vestígios de tal relação que marcaram modos de perceber as relações humanas. Assim, a relação entre literatura e religião entra em confluência (dia)lógica, compreendidas, então, como formas de produção discursiva. É a partir deste contexto de explanações que partimos do pressuposto de que tanto a literatura quanto a religião não subsistem sem atravessamentos histórico-ideológicos.

\section{A importância da perspectiva dialógica para a interpretação dos sa- beres religiosos e literários}

Para Souza e Albuquerque (2012), objeto e sujeito podem ser considerados no que diz respeito a uma delimitação de especificidades. Assim, na maior parte das ciências, se tem um objeto a conhecer e um indivíduo cognoscente. Porém, quando, no campo das Ciências Humanas, se trata da relação entre eu e um outro não se está tratando apenas de uma exterioridade desvinculada de uma interioridade, pois as relações entre eu e outro se estabelecem uma relação diferente daquela que se diz em relação ao sujeito e um objeto desprovido de interioridade, pois “" $[\mathrm{o}]$ pesquisador do campo das ciências humanas está, portanto, transitando no terreno das descobertas, das revelações, das tomadas de conhecimento, das comunicações, das produções de sentido entre o eu e o outro (SOUZA; ALBUQUERQUE,

\footnotetext{
${ }^{7}$ Aqui é importante um parênteses: neste caso, profano e sagrado não remetem à uma hierarquia valorativa que pressupõe evolução ou ignorância acerca de certas formas de perceber as relações humanas, mas dizem respeito ao encontro com a religiosidade. Neste contexto, o ato de "profanar" remete a uma (tentativa de) ausentar-se da participação dos deuses na vida comum. Trata-se de uma distinção que implica em ausência ou presença de religiosidade no bojo das relações humanas. O que se nota é q ue, ao invés de pensar a religiosidade como irracionalidade e fuga da realidade, Eliade traz contribuições no sentido de perceber a questão religiosa como algo que contribui, no decorrer da história das civilizações, para abranger perspectiva de explicação do mundo que nos rodeia, frente a tantas outras perspectivas.
}

https://periodicos.unifap.br/index.php/letras Macapá, v. 8, n. 3, $2^{\circ}$ sem., 2018 
2012, p. 110).

Há um preço caro a pagar se pensarmos que estamos nos terrenos da descontinuidade: a pretensa homogeneização de saberes e de conhecimentos parece relegar a pesquisa na universidade a lugares legitimados a priori o que, por vezes, impera um comodismo e um receio de adentrar em lugares pouco transitados. No caso em que nos referimos, as relações entre literatura e religião atravessadas por leituras de prisma dialógico promovem uma abertura para pensar o objeto literário e o objeto religioso como entidades inter-relacionadas. Isso para buscar a parte que falta e a falta que constitui o saber enquanto locus inesgotável que leva a outros saberes, diferentes dos que vêm sendo repetidos ad infinitum sob a égide de discursividades fundadoras que, ao invés de produzir olhares inusitados, reforçam repetições cômodas e esquemas interpretativos previamente estabelecidos.

\begin{abstract}
Ainda herdamos da modernidade algumas castas teóricas e posições impregnadas de uma razão reforçadoras de um ordenamento unilateral e de um sujeito ainda calcado em ideais iluministas que situavam o pesquisador como alguém 'esclarecido', dotado de saber que deve 'iluminar' e dizer o caminho que os outros devem seguir. Quando a transgressão de um pensamento uniforme se faz presente com ela

subvertem-se antigos idealismos filosóficos revelando a "selvagem impossibilidade" de um Eu soberano a partir do estilhaçamento da subjetividade. Não se trata do fim da filosofia, mas do filósofo como soberano da linguagem rompendo com a soberania do sujeito que filosofa. Não é apenas subjetivação, mas dessubjetivação no sentido de um desprendimento de si que põe em cena a descontinuidade da história: ela não é única nem uma só assim como não são únicas nem somente legítimas as teorias que foram colocadas sob a égide de um pensamento verdadeiro sustentado por aqueles que têm horror à fragmentação do saber e de reconhecer que todo conhecimento é constituído de algo que lhe falta. (SILVEIRA, 2018, p. 41)
\end{abstract}

Ao corroborar com uma perspectiva dialógico-sociológica da linguagem, em que as marcas constitutivas do humano estão engendradas em múltiplas esferas do saber (estas inter-relacionadas), recorremos a Medviédev (2016 [1928]), para ancorar nosso posicionamento. O estudioso russo, ao inserir a religião como um dos centros de saber humano, tipifica a religião como um dos diversos campos da criação ideológica, estando ao lado da ciência, arte, moral etc. Na perspectiva deste autor, teríamos um campo geral das Ideologias e as especificidades de cada esfera, que entram em contato e se complementam.

A perspectiva dialógica da linguagem, além de ter mobilizado os pressupostos de Bakhtin à concretude de uma filosofia antipsicologista, o que se averigua em Frendismo (em que reage criticamente ao psicologismo idealista alemão e ao positivismo em vigor na Europa), oferece aparatos para refletir sobre a natureza dialógica da consciência, como a ética da própria vida humana. Assim, seria, o dialogismo,

A única forma adequada de expressão verbal da autêntica vida do homem é o diálogo inconcluso. A vida é dialógica por natureza. Viver significa participar do diálogo: interrogar, ouvir, responder, concordar, etc. Nesse diálogo o homem participa inteiro e com toda a vida: com os olhos, os lábios, as mãos, a alma, o espírito, todo o corpo, os atos. Aplica-se totalmente na palavra, e essa palavra entra no tecido dialógico da vida humana, no simpósio universal. (BAKHTIN, 2006 [1979], p. 348)

Essas asserções propõem que a evolução da língua esteve vinculada às premissas da 
interação social. Bakhtin e o Círculo ${ }^{8}$ reavaliam e se posicionam axiologicamente contrários às percepções de que a enunciação seja ato individual, pois ela é também social: no instante em que fala, o locutor não apenas age, mas interage. Em Problemas da poética de Dostoievski cuja primeira edição foi redigida em1929 que se tem a definição de discurso mais explicitamente no último capítulo quando Bakhtin afirma: "Intitulamos este capítulo 'O discurso em Dostoievski' porque temos em vista que o discurso, ou seja, a língua em sua integridade concreta e viva”. Isso porque para Bakhtin interessa "[...] não a língua como objeto específico da linguística, obtido por meio de uma abstração absolutamente legítima e necessária de alguns aspectos da vida concreta dos discursos” (BAKHTIN, 1997 [1963], p.181). Neste contexto, a concepção discursiva de linguagem se opõe a concepções vigentes que apregoavam que a língua seria transparente ou expressão do pensamento, por exemplo. Contrariando o subjetivismo idealista (língua como expressão do pensamento) e o objetivismo abstrato (língua como sistema) o Círculo de Bakhtin "entende que a verdadeira substância da língua é constituída pelo fenômeno da interação verbal. É a interação verbal que constitui a realidade da língua" (SILVEIRA; ROHLING; RODRIGUES, 2012, p. 23)

Conforme reflexão de Santana e Francelino (2018, p. 237),

\begin{abstract}
Na concepção de linguagem proposta pelo chamado Círculo de Bakhtin, o enunciado constitui um elo da complexa rede de outros enunciados, estabelecendo com todos eles relações dialógicas de variados níveis e graus de complexidade. O enunciado encontra, em seu curso natural na comunicação discursiva, os enunciados de outrem, já impregnados das intenções e dos pontos de vista desse(s) outro(s), com o qual(is), inevitavelmente, adota uma compreensão responsiva ativa de concordância-discordância, convergência-divergência, tolerância-intolerância, não necessariamente de forma dicotômica. Portanto, há uma reação à palavra do outro, à visão de mundo do outro, de modo que, ao entrelaçar-se com o discurso alheio, o enunciado adentra um espaço saturado de diferentes posições axiológicas.
\end{abstract}

Então, em termos de permanência do sagrado e do religioso através de suas múltiplas linguagens, enquanto instâncias que perpassam a vida humana, recorremos a Todorov, o qual sintetizou, em termos de espaço-temporalidade, uma revolução no modo de pensar:

Há dois ou três séculos uma verdadeira revolução ocorreu na Europa: a referência ao mundo divino, encarnado pela religião, começou a dar lugar a valores puramente humanos. Ainda temos de lidar com um absoluto ou com um sagrado, mas ambos deixaram o céu e desceram à Terra. Não se trata mais de dizer que, desde essa época, para os europeus, "a religião morreu". Ela não está morta na medida em que, forma principal, senão única, da aspiração ao absoluto durante séculos, ela deixou sua marca nesse próprio traço humano (...) Entre todas as tentativas de pensar e viver o absoluto de maneira individual para fora tanto das religiões tradicionais quanto das religiões seculares políticas, gostaria de me ater a uma, a que interpreta essa experiência como a busca da beleza. (2011, p. 11,13)

Apesar das múltiplas interpretações sobre o fenômeno religioso dentro das produções literárias, o que propomos é a observação dialógica, na preservação de uma constituição de

\footnotetext{
8 Quanto à expressão "Círculo de Bakhtin", faz referência a um grupo de intelectuais que se reuniu com frequência entre 1919 e 1929 em cidades russas, como Nevel, Vitebsk e São Petersburgo para debater sobre ideias e propostas filosóficas. Constituía-se por pessoas de áreas diversificadas e profissões distintas, dentre os quais se destacam Mikhail M. Bakhtin, Valentin N. Volochinov e Pavel N. Medvedev. Outros integrantes eram Matvei I. Kagan, Ivan I. Kanaev, Maria V. Yudina e Lev. V. Pumpianski.
} 
sentidos que se concretizam na interrelação entre texto/discurso/autor-pessoa/autor-criador. Articulando a noção de literatura enquanto experiência de busca pela beleza, pensamo-la como um fenômeno artístico, campo de fatos culturais, através da qual o humano (des)estabiliza pressupostos, lugares epistemológicos e suas mais diversas criações.

\title{
3 Análise dialógica do poema "A falta que ama”, de Adélia Prado
}

\author{
A falta que ama \\ O meu saber da língua é um saber folclórico. \\ Muitos me arguirão deste pecado. \\ Não sei o que responder, \\ uma nuvem me tolda. \\ Me levanto com a alva, \\ encontro ameixas maduras no quintal, \\ uma ave nova que voa sem fugir de mim. \\ Nunca fui em Belo Vale, \\ mas amo esta cidade \\ porque meu pai passou nela, em romaria, \\ e voltou falando 'Belo Vale, porque Belo Vale', \\ este som de leite e veludo. \\ Quis dizer nêspera e não disse. \\ Só por causa da música que não entendo \\ ninguém me apedrejará. \\ Não invejo os deuses, porque não existem. \\ Os gênios, sim, os que dizem: \\ eis a forma nova, fartai-vos. \\ Como és belo, amado! Belo e perecível! \\ Tudo é sonho e escândalo, \\ congênita ambiguidade. \\ Se pudesse entender: o Filho de Deus é homem. \\ Mais ainda: o Filho de Deus é verbo, \\ eu viraria estrela ou girassol. \\ O que só adora e não fala.
}

Antes da análise dialógica, esclarecemos que a voz que fala, no poema, sob a perspectiva teórica na qual nos inscrevemos, não é da autora Adélia Prado, mas de um autor-criador (BAKHTIN, 2010 [1930-1934]). Portanto, há uma mobilização de dizeres, por parte do eulírico que, por sua vez, já são elementos do fazer artístico-poético.

Os dois primeiros versos são proferidos por um sujeito enunciativo que se direciona para si mesmo (O meu saber da língua é um saber folclórico) para justificar a percepção de outros sobre si (Muitos me arguirão deste pecado). Folclórico, neste contexto, remete ao que é próximo do popular, não erudito. O pecado de um poeta (ou poetisa) que tem "saber folclórico" é profanar o vernáculo, por exemplo, em um poema tecido em versos livres, desritmados, estilo que aponta mais para uma informalidade que para um cuidado (excessivo) com a forma, por exemplo (parnasianos que o digam). Em termos bakhtinianos, há um constante direcionamento subjetivo entre as instâncias eu-para-mim e outro-para-mim, na medida em que o sujeito poético vai se constituindo. As enunciações presentes dos versos três a sete conferenciam dúvida e incerteza por parte do autor-criador, e ao mesmo tempo a descrição de uma cenografia em que o já existente se confunde com a novidade do acontecimento: Não 
sei o que responder/ uma nuvem me tolda/[já acontecido, incerteza] Me levanto com a alval encontro ameixas maduras no quintal/ uma ave nova que voa sem fugir de mim [novidade].

Em perspectiva heterocientífica ${ }^{9}$, a primeira remissão feita ao religioso está no reconhecimento, por parte da personagem, de que o próprio saber linguístico está nos fundamentos dum horizonte folclórico. Assim, em nossa especificidade, tratamos do folclore como um saber cultural-religioso enraizado nas bases da nacionalidade brasileira e, conforme Ribeiro (2003), elemento nacionalista da literatura brasileira. $\mathrm{O}$ saber do eu-lírico é folclórico porque privilegia as bases de produção da terra de seu pai, no caso, de Belo Vale, conforme se demonstra nos versos a seguir:

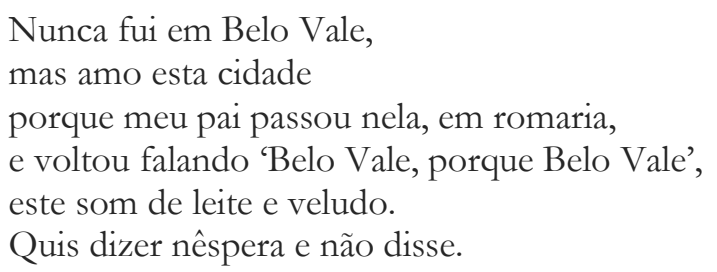

Apesar de nunca ter ido a Belo Vale, ou em romaria, a terra é sua por pertença memorialística, uma vez que seu pai passou por lá, e trouxe consigo o encantamento oriundo daquele lugar. Percebe-se que a palavra atuou como uma ponte ao conduzir duas consciências (BAKHTIN, 2006 [1979]). Nas tessituras deste filósofo soviético, em Cultura popular na Idade Média e no Renascimento: o contexto de François Rabelais (2010 [1965]), esses efeitos discursivos estão na base do conhecimento religioso e folclórico como a remissão memorialística às marcas da manifestação da cultura popular, as quais, "na sua heterogeneidade, refletem um mesmo aspecto cômico do mundo, estão estreitamente inter-relacionadas e combinamse de diferentes maneiras" (BAKHTIN, 2010 [1965], p. 4). A voz que ecoava em seus ouvidos era tão doce e afável que foi comparada ao som de leite e veludo, porém, poderia também ter sido comparada à véspera, de cujas sementes se produzem os licores mais finos. Assim como o riso na idade média estava relegado para fora das esferas oficiais de seriedade que predominavam no período em que Bakhtin (2010 [1965]) analisa o contexto de Rabelais, a cultura popular está "repleta de estratificações e linguagens não-oficiais descentralizadoras” (TEZZA, 2003, p. 22). É o caso do religioso frente ao saber científico e também dos poemas de versos livres frente às formas tradicionais de versificação métrica. Trata-se de uma carnavalização de estruturas hierárquicas relacionadas historicamente a uma linguagem oficial e centralizadora.

\footnotetext{
Só por causa da música que não entendo ninguém me apedrejará.

Não invejo os deuses, porque não existem.

Os gênios, sim, os que dizem:
}

\footnotetext{
${ }_{9}$ Apenas uma vez em toda sua obra Bakhtin utiliza o termo aludindo ao fato de que é impossível estudar a linguagem sem considerar o outro, a alteridade constitutiva e isso, no âmbito do dialogismo que a impregna e caracteriza, faz com que não seja possível adotar uma postura científica no mesmo modo que as ciências exatas o fazem, por exemplo. Daí a ideia de uma perspectiva heterocientífica. Mais explicitamente o que ele afirma em Estética da criação verbal é:

A interpretação dos sentidos não pode ser científica, mas profundamente cognitiva. Pode servir diretamente à prática vinculada às coisas. Cumpre reconhecer a simbologia não como forma não científica, mas como forma heterocientífica do saber, dotada de suas próprias leis e critérios internos de exatidão (BAKHTIN, 2006 [1979], p. 399).
} 


\section{eis a forma nova, fartai-vos.}

Como és belo, amado! Belo e perecível!

Tudo é sonho e escândalo,

congênita ambiguidade.

Continua a voz a narrar: não é porque há um desconhecimento sobre as músicas cantadas e festejadas que as pessoas a apedrejarão. No folclore, além dos paralelismos recorrentes dos povos primitivos, do que se manteve até a segunda metade do século XX, "quase todas as festas religiosas possuíam um aspecto cômico popular e público, consagrado, também, pela tradição". (BAKHTIN, 2010 [1965], p. 4). Por conseguinte, entre o plano transcendental e o racional, é melhor pausar no concreto, no palpável, antes a materialização que o plano das ideias: Não invejo os deuses, porque não existem/ Os gênios, sim, os que dizem: eis a forma nova, fartai-vos. Neste caso, os gênios simbolizam a ciência, que sucede a mitologia. Então, em teores poéticos, tece elogios a um amado: Como és belo, amado! Belo e perecivel! Tudo é sonho e escândalo/ congênita ambiguidade.

Percebe-se, então, que ocorre um atravessamento de discursos: o mito religioso precede a ciência e o saber científico é mais pomposo que o saber informal das ruas, por exemplo. Sob esta lógica, o que se pode comprovar é o que a ciência afirma e esta trata de coisas sérias, coisas que existem, mas os deuses, estes não existem, então não há porque invejálos. A discursividade divina e científica repousam em lugares diferentes e emitem signos ideológicos de tom valorativo hierarquizador. Nada de novo no front. Tais discursos estão presentes no cotidiano da vida em comunidade. Neste contexto, sobre a constante remissão a outros (discursos), afirma Fiorin que

O enunciador, para constituir um discurso, leva em conta o discurso de outrem, que está presente no seu. Por isso, todo o discurso é inevitavelmente ocupado, atravessado, pelo discurso alheio... Não há um objeto que não apareça cercado, envolto, embebido de discursos. Por isso, todo discurso que fale de qualquer objeto não está voltado para a realidade em si, mas para os discursos que a circundam. Por conseguinte, toda palavra dialoga com outras palavras, constitui-se a partir de outras palavras, está rodeada de outras palavras. (FIORIN, 2006, p. 19).

Considerando discursos que circundam enunciados vale acentuar na teoria bakhtiniana um ponto nodal é a palavra alheia. Assim, as relações de sentido entre enunciados não remetem a um indivíduo fundador, produtor de enunciados ou a uma intencionalidade geradora de sentidos porque os discursos estão impregnados das palavras de outrem e não somos nem os primeiros e nem os últimos elos da cadeia de comunicação discursiva. No tangente, então, à religião e à temática da divindade, nos fragmentos que se seguem o autorcriador as mobiliza de forma sintagmática.

Se pudesse entender: o Filho de Deus é homem.

Mais ainda: o Filho de Deus é verbo,

eu viraria estrela ou girassol.

O que só adora e não fala.

Trouxemos esse destaque da voz poética, no instante em que a personagem se remete a Deus, remetendo, na ótica de Magalhães (2009, p. 20-21), a uma concepção monoteísta de Deus correlacionando a essa noção a consciência messiânica que define o horizonte não apenas de uma história religiosa, mas do processo histórico civilizacional do Ocidente. A religião, enquanto re-ligare, promove atravessamentos do discurso bíblico, convocando a 
consciência humana a um constante reencontro com Deus. No caso em explanação, a tradição bíblica atua como uma seiva literária, numa caixa simbólica de narrativas para diversas apropriações críticas e criativas.

Há um conflito entre duas afirmativas constantes nas entrelinhas bíblicas: Por uma instância o Filho de Deus, Jesus Cristo, se configura como homem, pelas vias da encarnação, passou pelo processo do nascimento, e viveu entre os homens, até ser crucificado. Há também, por parte do autor criador, menção a uma descrição que o apóstolo João faz de Jesus (Jo 1,1): No princípio era o Verbo. E o Verbo estava com Deus. E o Verbo era Deus. Em uma instância verboideológica, ou seja, ultrapassando-se os limites sintagmático-linguísticos, Santana e Lima (2018) nos ajudam a compreender melhor o texto, afirmando que João estava concretizando discursivamente a divindade de Jesus Cristo, nomeando-o de Verbo. Esses trechos bíblicos, então, configurar-se-iam como "possuindo riquezas linguístico-discursivas de cunho teológico acerca de Jesus, e este como ser Divino". (SANTANA; LIMA, 2018, p. 201).

Por fim, reacentuamos com os termos de MacDonald, para quem "“'Vindo ao mundo, Cristo revelou perfeitamente como Deus é. Morrendo por nós na Cruz, ele demonstrou o quanto Deus nos ama. Assim, Cristo é o verbo vivo de Deus para o homem, a expressão dos pensamentos de Deus". (MACDONALD, 2008, p. 235). Diante de tais assertivas, que gerenciam os saberes humanos desde o primeiro século d.C, Adélia Prado, enquanto autorpessoa, revestiu-se de um autor-criador que mobiliza dubitavelmente (eu viraria estrela on girassol/ O que só adora e não fala) dois saberes: o Jesus-homem (intercessor) e o Jesus-Deus, o qual é nomeado de Verbo.

Ao trazer o discurso do Filho de Deus encarnado em verbo se faz uma pressuposição metapoética, pois o que as palavras poéticas, assim como as palavras do verbo divino, fazem é tornar existentes as coisas e os acontecimentos a que se referem. Tem-se a manifestação de um desejo de alcançar o terreno da natureza tornando-se estrela ou girassol por ação do verbo divino que torna as coisas existentes através da palavra (o enunciado Fiat lux, do livro do Gênesis, é um exemplo disso). De poeta que tem o saber folclórico se chega ao desejo de não mais enunciar, só adorar o divino. Logo, a religiosidade, neste caso, não é apresentada como irracional ou hierarquicamente inferior aos saberes científicos, mas como dotada de uma natureza ontológia que permite a transformação da poetisa em um ser que ao emudecer, põe-se em estado de contemplação divina, adorando sem falar. Busca-se, como havia afirmado anteriormente Todorov, uma experiência contemplativa estética, de beleza.

Tais signos linguístico-discursivos não apenas conduzem à interpretação de relações dialógicas entre o religioso e o literário, mas constituem marcas do dizer poético que, por sua vez, iluminam toda a visibilidade ético-responsiva. Perceba-se que o discurso literário poético a todo o instante foi constitutivamente atravessado pelo discurso religioso, o qual lhe garante novas formas de ser/estar/viabilizar a construção de impressões e pontos de vista acerca do fazer poético. Mais do que ser englobada pelo conhecimento empírico tanto religião quanto poema se inscrevem no campo da incompletude fundante ( e pudesse entender).

Assim, a poesia não se esgota em rimas e formas, mas na produção de sentidos que podem se aproximar de saberes folclóricos ao invés de pautar-se numa ciência das métricas harmoniosas, como foi no Parnasianismo, por exemplo. Logo, religião e literatura se consubstanciam no sentido em que ambas remetem ao encontro com as relações humanas e as repostas a configurações específicas de produzir sentidos, seja em relação ao sagrado, seja em relação a formas de fazer poesia.

https://periodicos.unifap.br/index.php/letras

Macapá, v. 8, n. 3, $2^{\circ}$ sem., 2018 


\section{Considerações finais}

O compromisso ético de cada pesquisador no campo das Ciências Humanas se relaciona com o fato de que o objeto a ser estudado não se reduz a um inanimado isento de interioridade. Recusar esquemas interpretativos aprioristicamente estabelecidos é de uma responsabilidade impar considerando que uma das mais profundas contribuições do Círculo de Bakhtin para a nossa era é a de refutar a homogeneizações voltando à atenção para o mundo à nossa volta. Isso porque todo discurso é atravessado pelo discurso de outrem que, por sua vez, nos constitui e constitui os modos de interpretar os contextos em que nos situamos.

Considerando literatura e religião como entidades inter-relacionadas, esvaímos de nos inscrevermos no senso comum que apregoa a religião no campo da irracionalidade visto que a (falta de) religiosidade também é uma forma de perceber como se dá o estabelecimento das relações humanas no decorrer dos tempos. Diante disso, visamos discursivizar a importância das Relações dialógicas para a interpretação dos saberes religiosos e literários e analisar, dialogicamente, o poema "A falta que ama", de Adélia Prado reconhecendo não como uma tarefa acabada e única, mas aberta a uma falta constituinte, característica essencial das Ciências Humanas que consideram a alteridade no bojo das considerações interpretativas que vão sendo tecidas. Esperamos que este trabalho possa florescer e frutificar flores e sementes para heterocientificar o saber na universidade para que, reconhecendo-nos incompletos, possamos enveredar pelos caminhos do desconhecido e do inusitado para, cada vez mais, ver o que nos olha e por nós não passe negligenciadamente despercebido.

\section{Referências}

BAKHTIN, Mikhail. A Cultura popular na Idade Média e no Renascimento - o contexto de François Rabelais. Tradução de Iara Frateschi Vieira. São Paulo - Hucitec, 2010 [1965].

Estética da Criação Verbal. Tradução do russo por Paulo Bezerra. 5. ed. São Paulo: Martins Fontes, 2006 [1979].

O Freudismo: um esboço crítico. 2. ed. São Paulo: Perspectiva, 2012 [1927].

O discurso no Romance. (1934-35). In:

Questões de literatura e de estética - A Teoria do Romance. Equipe de tradução (do russo) Aurora Fornoni Bernardini; José Pereira Júnior; Augusto Góes Júnior; Helena Spryndis Nazário; Homero Freitas de Andrade. 6. edição. Editora Hucitec - São Paulo, 2010 [1930-1934].

Problemas da poética de Dostoievski. Tradução do russo por Paulo Bezerra.

3. Ed. Rio de Janeiro: Forense Universitária, 1997 [1963].

BÍBLIA SAGRADA. Antigo e Novo Testamento. Belo Horizonte: Atos, 2012.

CÔRREA, Guilherme Torres; RIBEIRO, Victória Maria Brant. Dialogando com Bakhtin: algumas contribuições para a compreensão das interações verbais no campo da saúde. Interface Comunicação e Educação, v. 16, n. 41, p. 331-341, 2012.

ELIADE, Mircea. O sagrado e o profano: a essência das religiões. São Paulo: Martins Fontes: 1992.

FIORIN, José Luis. Introdução ao pensamento de Bakhtin. São Paulo: Ática, 2006. MACDONALD, William. Comentário Bíblico Popular - Novo Testamento. Traduzido por Suzana Klassen e Vanderlei Ortigoza. São Paulo: Mundo Cristão, 2008. 
MACHADO, Irene. A questão espaço-temporal em Bakhtin: cronotopo e exotopia. In: STAFUZA, Grenissa; PAULA, Luciane de (Orgs.). Círculo de Bakhtin: teoria inclassificável. Campinas: Mercado das Letras, 2010, p. 203-234.

MAGAlHÃeS, A. Deus no espelho das palavras. 2. ed. São Paulo: Paulinas, 2009.

MEDVIÉDEV, Pável Nikoláievitch. O Método Formal nos estudos literários: introdução a uma poética sociológica. Tradução de Sheila Camargo Grillo e Ekaterina Vólkova Américo. São Paulo: Contexto, 2016.

PRADO, Adélia. O coração disparado. Rio de Janeiro: Record, 2013.

RIBEIRO, Cristina Betioli. Folclore e Nacionalidade na Literatura Brasileira do século XIX. 2003. Dissertação (Mestrado em Teoria e História Literária) - Universidade Estadual de Campinas, Campinas, 2003.

SANTANA, Wilder Kleber Fernandes. FRANCELINO, Pedro Farias. A representação linguístico-discursiva de Jesus Cristo em seu sermão sobre o cumprimento do amor a partir do evangelho segundo são Mateus. Revista da Anpoll, v. 1, n 45, p. 233-247, Florianópolis, Maio/Ago. 2018.

. LIMA, Francisco de Assis da Silva. Uma apologética à divindade suprema de Jesus Cristo. In: SANTANA, Wilder Kleber Fernandes de; LIMA, Francisco de Assis da Silva (Orgs.) Teologia e Vida Cristã na Pós-modernidade. João Pessoa: Ideia, 2018, p. XX$\mathrm{XX}$.

SILVEIRA, Ana Paula Kuczmynda da; ROHLING, Nívea; RODRIGUES, Rosângela Hammes. A análise dialógica dos gêneros do discurso e os estudos do letramento: glossário para leitores iniciantes. Florianópolis: DIOESC, 2012.

SILVEIRA, Éderson Luís. A (des)continuidade das Letras (in)fiéis: notas sobre relações (im)possíveis entre a Literatura, a Linguística e (os estudos d)a Linguagem. In: PAZ, José Flávio da Paz; GUTIERREZ, Néstor Raúl Gonzalez (Orgs.). Retextualização - Arte, literatura e linguagem. São Paulo: Agbook, 2018, v. 1, p. 37-44.

SOUZA, Solange Jobim e; ALBUQUERQUE, Elaine Deccache Porto e. A pesquisa em ciências humanas: uma leitura bakhtiniana. Bakhtiniana, São Paulo, v. 7, n. 2, p. 109-122, Jul./Dez. 2012.

TODOROV, T. A beleza salvará o mundo: Wilde, Rilke e Tsvetaeva: os aventureiros do absoluto. Rio de Janeiro: DIFEL, 2011.

VATTIMO, G. Depois da cristandade: por um cristianismo não religioso. Rio de Janeiro: Record, 2004. 